\title{
Relationship between Type 2 Diabetes Mellitus-Primary Open Angle Glaucoma Comorbidity and Lifestyle Factors In Imo State, Nigeria
}

\author{
Eberendu Izuchukwu Francis, Justina Kwaskebe, Abanobi Okwuoma Chi, Ozims Stanley James
}

\begin{abstract}
Background: Comorbidity is a major health concern all over the world with a huge number of people diagnosed each day. This work studied the relationship between comorbidity of type 2 diabetes mellitus-primary open angle glaucoma(T2DM-POAG) and lifestyle factors(cigarette smoking, alcohol consumption and physical activity)in Imo state, South Eastern Nigeria with the aim of finding the protective factors for the comorbidity.

Methods: The study adopted a population based case-control study design. The subjects concerned in this study were 198 adults aged, 40 years and above, diagnosed of T2DM-POAG comorbidity (99 cases) and those without the comorbidity (99 controls). Variables taken into consideration were: physical activity, cigarette smoking and alcohol consumption. Data analyses were performed using IBM-SPSS statistics version 23 for data analyses. Microsoft Excel 2010 was used in drawing charts. Measured variables were summarized using descriptive statistics of mean and standard deviation. Graphical representations such as bar chart and pie charts were used to represent some of the results. Weighted test such as Wald test was used to test for significant factors in the model. The factors were considered significant at $5 \%$ level. Odds ratio were computed so as to measure the strength of the association between each of the exposures (the risk factors of interest) and the outcome. Confidence interval (CI) at $95 \%$ level was also calculated for each odds ratio.
\end{abstract}

Results: Lifestyle factors such as physical exercise, cigarette smoking, and alcohol intake were found significant in this study. In terms of frequency, doing exercise everyday was significant $(p=0.005)$, as well as 3 times in a week $(p=0.005)$. for those who engage in exercise for up to 3 time in a week, the odds for T2DM -POAG comorbidity was found to be $81 \%$ lower (ie. 1-0.19)\% compared to those that never do exercise(matched) $(\mathrm{OR}=\mathbf{0 . 1 9}, 95 \%$ CI $=0.059-0.599)$. Similarly T2DM -POAG comorbidity risk was found to be $90 \%$ (ie 1-10)\% lower on the subjects that practice exercise everyday compared to the ones that never do exercise(matched), not doing exercise showed lower risk of T2DM -POAG comorbidity $(O R=0.10,95 \%$ CI $=0.200-2.499)$. Exposure to cigarette smoking showed positive relationship with T2DM -POAG comorbidity. In this study, being exposed to cigarette smoking was found to be significantly associated with up to two times higher risk of T2DM -POAG comorbidity compared to non-exposure cigarette smoking (OR

Eberendu Izuchukwu Francis, Department of Public Health, Imo State University, Owerri, Imo State Nigeria

Justina Kwaskebe, Department of Public Health, AdelekeUniversity,Ede, Osun State Nigeria

Abanobi Okwuoma, Department of Public Health, Federal University of Technology Owerri, Imo State Nigeria

Ozims Stanley James, Department of Public Health, Imo State University, Owerri, Imo State Nigeria
$=2.02,95 \% \mathrm{CI}=1.075-3.814, \mathrm{p}=0.029)$. Higher risk of T2DM -POAG comorbidity was obtained for the study participants that consume alcohol $(\mathrm{OR}=2.47,95 \% \mathrm{CI}=1.191-5.142)$. While the type of alcohol consumed was not a significant factor of T2DM -POAG comorbidity in this study $(p>0.05)$, the frequency of alcohol consumption was found significant in such a way that taking alcohol sparingly attracts $52 \%$ (ie 1- 0.48) \% lesser risk T2DM -POAG comorbidity than taking it often times $(\mathrm{OR}=0.48,95 \% \mathrm{CI}=0.256-0.910)$.Similar to the univariate analysis, significant lifestyle factors found in the multivariate model include frequency of doing exercise $(p=0.001)$, exposure to cigarette smoking $(p=0.029)$, alcohol intake $(p=0.002)$, and frequency of alcohol consumption $(p=0.001)$. The adjusted odds ratio indicates that the odds for T2DM-POAG comorbidity were more on cigarette smoking by 2.6 time (95\% CI $=1.104$ -6.237) compared to non-smokers, more on alcohol intake by 3.15 times $95 \%$ CI $=1.541-6.447$ ) compared to non-alcohol consumers, but less on taking alcohol sparingly by $79 \%$ ( (i.e $1-0.21) \% 95 \% \mathrm{CI}=\mathbf{0 . 1 0 3}-\mathbf{0 . 4 2 5}$ ) compared to taking alcohol often. Implications for the control of the comorbidity were discussed in line with the research questions.

Conclusion: As little information on T2DM-POAG comorbidity is available in Nigeria, this study contributes to better understanding of the protective factors for this comorbidity. Research work like this, tend to broaden the perspectives related to factors that play a vital role during the designing of preventive procedures and development of public health interventions regarding T2DM-POAG comorbidity. Protective factors of T2DM-POAG comorbidity, such as physical activity, cigarette smoking alcohol consumption which are modifiable, can be promoted to the population for better T2DM-POAG comorbidity prevention and control.

Index Terms - Comorbidity, Lifestyle factors, Type 2 Diabetes mellitus-Primary open angle comorbidity.

\section{INTRODUCTION}

Comorbidity of non-communicable chronic diseases is a major health concern all over the world, since they are associated with high rates of morbidity and mortality and high costs to the public health systems[20]. Type 2 diabetes mellitus-primary open angle glaucoma comorbidity is one of the leading causes of death and visual impairment globally. There appears to be an increase in the incidence of T2DM-POAG comorbidity in recent decades [11]. The increase in the number of persons with the comorbidity may be probably due to population growth, aging, urbanization and lifestyle factors.

Diabetes is a chronic non-communicable endocrine metabolic disease that has caught the attention of public health 
community researchers with little or no attention paid to the comorbidity of diabetes with other diseases[10]. Primary open angle glaucoma is the major cause of irreversible blindness and other visual impairments[12].

Despite the increase in T2DM-POAG comorbidity burden, interventions are still poor and epidemiological data are scarce. Several studies have suggested that diabetes may be associated with increased risk of primary open angle glaucoma [5][2][8][15][12][18] whereas some other studies see the two as two incidental disorders in which the deductible comorbidity case is due to a separate third disorder[15][18]. Investigation of the risk factors for the comorbidity of T2DM-POAG is vital for the prevention of the comorbidity, especially since the incidence of T2DM-POAG comorbidity is on the rise [21] hence, this study.

\section{Materials and Methods}

The study was a population based case-control study. Data were obtained from a total of 198 subjects comprising, 99 cases and 99 controls who were recruited into the study through multi-stage sampling technique in the study area. The LGAs, wards, villages and households were randomly selected in the three senatorial zones of Imo State. The sampling involved three stages:

Stage 1: Involved the selection of LGAs to be studied. Two wards from each LGAs were selected using simple random sampling by balloting.

Stage II: Involved the selection of villages, of which one villages each from the each ward were selected using simple random sampling by balloting.

Stage III: Involved the selection of the households/subjects that were studied using multistage sampling method. The households were randomly sampled.

Life style data (Physical activity, alcohol consumption and cigarette smoking habit), T2DM status, POAG status, eye examination and laboratory tests, including glycosylated haemoglobin (as a measure of T2DM and glycemic control) were collected during the study. After collecting socio-demographic data (Age, sex, occupation, marital status, educational level,), present and past medical history including type and duration of diabetes, a comprehensive eye evaluation was performed to determine the presence or otherwise of primary open angle glaucoma(POAG). Visual acuity was measured using snellens chart placed at a $6 \mathrm{~m}$ distance from the patient. Ophthalmoscopic examination of the eye was performed under dim illumination. Schiotz tonometer was used to measure the IOP of the subjects. Penlight estimation was used to estimate the anterior chamber angle of the subjects who were aged $\geq 40$ years and who must have lived in Imo State atleast 6months before the commencement of the study.

Data were collected using three instruments: Structured Risk assessment questionnaire, Physical measurements,
Biochemical assessments. A pre-tested, self-administered, structured risk assessment questionnaire based on WHO stepwise approach to chronic disease risk factor surveillance (STEPS) instrument was developed and used to capture data on T2DM-POAG comorbidity.The language of the questionnaire was English.

All subjects who tested positive to T2DM-POAG comorbidity and controls(to rule out false negative results) were sent to endocrine unit and of federal medical centre Owerri and optometric clinic of Imo State University Owerri respectively were confirmatory tests were performed by the physician on the cases and controls enrolled into the study. The study commenced in the month of May2019 and lasted till December, 2019.

\section{Data Analysis Method}

Data analysis was performed using IBM-SPSS statistics version 23 (SPSS Inc. Chicago, USA) for data analyses. Microsoft Excel 2010 was used in drawing charts. Descriptive statistics was used to summarize the data. The frequencies distribution of the variable characteristics were computed by case and control and presented in a table of distribution which were all expressed as the percentage of the distribution. Measured variables were summarized with mean and standard deviation Graphical representations such as bar chart bar was used to represent some of the results.

The risk factors of T2DM-POAG comorbidity were determined in a logistic regression. Which comprised of univariate (unadjusted) and multivariate (adjusted) model. T2DM-POAG comorbidity was used as the model outcome variable in the model while the risk factors assessed were entered as predictor variables in the model. Weighted test such as Wald test was used to test for significant factors in the model. The factors were considered significant at 5\% level. Odds ratio were computed so as to measure of the strength of the association between each of the exposures (the risk factors of interest) and the outcome. Confidence interval (CI) at $95 \%$ level was also calculated for each odds ratio. Probability value (p) was used to interpret significant risk factors at $5 \%$ level hence $\mathrm{p}$ less than $5 \%$ was considered significant for the risk factors.

\section{RESULTS}

A total of 198 subjects were available for analysis with equal number of cases and control (99 each).The distribution for lifestyle characteristics of the subjects is presented on Table 1 . The overall age group that contained the highest number of study participants was the $56-60$ years old with $47(23.7 \%)$ and was closely followed by the $61-65$ years old with 46 $(23.2 \%)$ and the 51 - 55 years with $45(22.7 \%)$ respectively. 66-older age group had the least participant with 13(6.6\%) and was closely followed by $46-50$ age group with $23(11.6 \%)$ and finally 40-45 age group with 24(12.1\%).

Lifestyle factors such as physical exercise, cigarette smoking, and alcohol intake were found significant in this study (Table 1) below. In terms of frequency, doing exercise everyday was significant $(\mathrm{p}=0.005)$, as well as 3 times in a week $(\mathrm{p}=0.005)$. 
for those who engage in exercise for up to 3 time in a week, the odds for T2DM -POAG comorbidity was found to be $81 \%$ lower (ie. 1-0.19)\% compared to those that never do exercise $(\mathrm{OR}=0.19,95 \% \mathrm{CI}=0.059-0.599)$. Similarly T2DM -POAG comorbidity risk was found to be $90 \%$ (ie $1-10$ ) $\%$ lower on the subjects that practice exercise everyday compared to the ones that never do exercise, not doing exercise showed lower risk of T2DM -POAG comorbidity $(\mathrm{OR}=0.10,95 \% \mathrm{CI}=0.200-2.499)$

Exposure to cigarette smoking showed positive relationship with T2DM -POAG comorbidity. In this study, being exposed to cigarette smoking was found to be significantly associated with up to two times higher risk of T2DM -POAG comorbidity compared to non-exposure cigarette smoking $(\mathrm{OR}=2.02,95 \% \mathrm{CI}=1.075-3.814, \mathrm{p}=0.029)$. The average number of cigarette smoked per day were found to be 8.36 (standard deviation $=3.75$ ) and 8.84 (standard deviation $=4.29$ ) among the control and the case groups. Clearly, the number of cigarette smoked per day could lead to rise in T2DM -POAG comorbidity (coefficient $=0.154$ ). The result of this study indicates that for every single addition to the number of cigarette smoked per day could probably attract a 1.17 significant risk of T2DM $-\mathrm{POAG}$ comorbidity $(\mathrm{OR}=$ $1.17,95 \% \mathrm{CI}=1.035-1.310, \mathrm{p}=0.011)$.

Alcohol consumption is another significant risk factor for T2DM -POAG comorbidity in this study ( $\mathrm{p}=0.015)$. Higher

Table 1: Lifestyle Factors and T2DM -POAG Comorbidity among the Study Group (Univariate Logistic Regression Method)

\begin{tabular}{|c|c|c|c|c|c|c|}
\hline \multirow[t]{2}{*}{ Lifestyle factors } & \multirow[t]{2}{*}{ Total } & Control & Case & \multirow[t]{2}{*}{ Coef } & \multirow[t]{2}{*}{$\mathbf{p}$} & \multirow[t]{2}{*}{ OR $(95 \%$ CI $)$} \\
\hline & & $\mathrm{N} \quad(\%)$ & $\mathrm{N} \quad(\%)$ & & & \\
\hline
\end{tabular}

Exercise and physical exertion in leisure

time

Reading, watching TV, or other sedentary activity

walking, cycling, or other forms of

exercise at least

$\begin{array}{lllll}122 & 66 & 54.1 & 56 & 45.9\end{array}$

participation in recreational sports, heavy gardening, etc(note: duration of activity at least 4 hours a week)

Participation in hard training or sports competitions, regularly several times a week.

Combined options

Frequency of doing exercise

Never

less than once a week

once a week

3times a week

approximately everyday

Exposure to cigarette smoking

No

Yes

Average number of cigarette smoked

per day $( \pm$ std dev) risk of T2DM -POAG comorbidity was obtained for the study participants that consume alcohol. Among the participant that do consume alcohol, the odd of T2DM -POAG comorbidity was found to be approximately 2.5 folds high compared to that of the matched non- alcohol intake ones $(\mathrm{OR}=2.47,95 \% \mathrm{CI}=1.191-5.142)$. While the type of alcohol consumed was not a significant factor of T2DM -POAG comorbidity in this study $(\mathrm{p}>0.05)$, the frequency of alcohol consumption was found significant in such a way that taking alcohol sparingly attracts $52 \%$ (ie 1 $0.48) \%$ lesser risk T2DM -POAG comorbidity than taking it often times $(\mathrm{OR}=0.48,95 \% \mathrm{CI}=0.256-0.910)$.

Similar to the univariate analysis, significant lifestyle factors found in the multivariate model include frequency of doing exercise $(\mathrm{p}=0.001)$, exposure to cigarette smoking ( $\mathrm{p}$ $=0.029$ ),

alcohol intake ( $\mathrm{p}=0.002)$, and frequency of alcohol consumption ( $\mathrm{p}=0.001)$. The adjusted odds ratio indicates that the odds for T2DM-POAG comorbidity were more on cigarette smoking by 2.6 time (95\% CI $=1.104-6.237$ ) compared to matched non-smokers, more on alcohol intake by 3.15 times $95 \% \mathrm{CI}=1.541-6.447$ ) compared to matched non-alcohol consumers, but less on taking alcohol sparingly by $79 \%$ ( (i.e $1-0.21) \% 95 \% \mathrm{CI}=0.103-0.425$ ) compared to taking alcohol often.

34

34

22

13

38.2

21

9

40.9

13

61.8

0.644

0.105

$1.90(0.875-4.145)$

12

10

6

50.0

(1)

43

89

$6 \quad 60.0$

6

50.0

$18 \quad 37.5$

30

59.1

0.532

0.258

$1.70(0.667-4.278)$

30

$\begin{array}{lll}30 & 14 & 50.0 \\ 16 & 16 & 76.2\end{array}$

$\begin{array}{lll}14 & 12 & 85.7\end{array}$

$\begin{array}{lll}144 & 79 & 54.9\end{array}$

$\begin{array}{lll}56 & 21 & 37.5\end{array}$

$8.36 \pm 3.75$

$35 \quad 62.5$

50.0

0.164

0.786

$1.18(0.360-3.860)$

40.0

$-0.241$

0.719

$0.79(0.21-2.935)$

0.002

$49 \quad 55.1$

$\begin{array}{ll}49 & 55.1 \\ 14 & 50.0\end{array}$

14

$5 \quad 23.8$

$2 \quad 14.3$

$-0.346$

0.401

$\begin{array}{ll}-0.100 & 0.289\end{array}$

$-0.234 \quad 0.005$

$-0.234 \quad 0.005$

$0.74(0.358-1.507)$

$0.60(0.234-1.541)$

$0.19(0.059-0.599)$

$0.10(0.200-2.499)$

$65 \quad 45.1$

0.705

$0.029 *$

2.02 (1.075-3.814)

8.844 .29

0.154

$0.011 *$

1.17 (1.035-1.310)

\section{Alcohol Intake Status}

No

Yes

$\begin{array}{ccccc}40 & 27 & 67.5 & 13 & 32.5 \\ 160 & 73 & 45.6 & 87 & 54.4 \\ & & & & \\ 50 & 24 & 48.0 & 26 & 52.0\end{array}$

$0.906 \quad 0.015^{*} \quad 2.47(1.191-5.142)$

Alcohol Type $(\mathbf{n}=160)$

Beer 
Relationship between Type 2 Diabetes Mellitus-Primary Open Angle Glaucoma Comorbidity and Lifestyle Factors In Imo State, Nigeria

\begin{tabular}{lcccccccc}
\hline Spirit & 46 & 17 & 37.0 & 29 & 63.0 & 0.454 & 0.276 & $1.57(0.696-3.562)$ \\
Wine & 46 & 23 & 50.0 & 23 & 50.0 & -0.080 & 0.845 & $0.92(0.414-2.057)$ \\
Combined drinks & 18 & 9 & 50.0 & 9 & 50.0 & -0.080 & 0.884 & $0.92(0.314-2.712)$ \\
Frequency of alcohol intake & & & & & & & & \\
Often & 77 & 28 & 36.4 & 49 & 63.6 & & & \\
Sparingly & 83 & 45 & 54.2 & 38 & 45.8 & -0.729 & $.0 .024 *$ & $0.48(0.256-0.910)$ \\
\hline
\end{tabular}

Asterisks $(*)=5 \%$ significant, coef $=$ coefficient, $\mathbf{C I}=95 \%$ confidence Interval, $\mathrm{OR}=$ Odds ratio

Table 2: Lifestyle Factors and T2DM -POAG Comorbidity among the Study Group (Multivariate Logistic Regression Method)

\begin{tabular}{|c|c|c|c|c|c|c|c|c|}
\hline \multirow[t]{2}{*}{ Lifestyle factors } & \multirow[t]{2}{*}{ Total } & \multicolumn{2}{|c|}{ Control } & \multicolumn{2}{|c|}{ Case } & \multirow[t]{2}{*}{ coef } & \multirow[t]{2}{*}{$\mathbf{p}$} & \multirow[t]{2}{*}{$\operatorname{AOR}(95 \% \mathrm{CI})$} \\
\hline & & $\mathbf{N}$ & $(\%)$ & $\mathbf{N}$ & $(\%)$ & & & \\
\hline \multicolumn{7}{|l|}{$\begin{array}{l}\text { Exercise and physical exertion in } \\
\text { leisure time }\end{array}$} & \multicolumn{2}{|l|}{0.050} \\
\hline $\begin{array}{l}\text { Reading, watching TV, or other sedentary } \\
\text { activity }\end{array}$ & 122 & 66 & 54.1 & 56 & 45.9 & & & \\
\hline $\begin{array}{l}\text { walking, cycling, or other forms of } \\
\text { exercise at least }\end{array}$ & 34 & 13 & 38.2 & 21 & 61.8 & 0.824 & 0.118 & $2.28(0.810-6.412)$ \\
\hline $\begin{array}{l}\text { participation in recreational sports, heavy } \\
\text { gardening, etc(note: duration of activity } \\
\text { at least } 4 \text { hours a week) }\end{array}$ & 22 & 9 & 40.9 & 13 & 59.1 & -0.162 & 0.793 & $0.85(0.255-2.837)$ \\
\hline $\begin{array}{l}\text { Participation in hard training or sports } \\
\text { competitions, regularly several times a } \\
\text { week. }\end{array}$ & 12 & 6 & 50.0 & 6 & 50.0 & 1.787 & 0.059 & $6.0(0.938-38.01)$ \\
\hline Combined options & 10 & 6 & 60.0 & 4 & 40.0 & -1.463 & 0.074 & $0.23(0.047-1.153)$ \\
\hline Frequency of doing exercise & & & & & & & $0.001 *$ & \\
\hline Never & 43 & 18 & 37.5 & 30 & 62.5 & & & \\
\hline less than once a week & 89 & 40 & 44.9 & 49 & 55.1 & -0.188 & 0.590 & $0.83(0.419-1.639)$ \\
\hline once a week & 30 & 14 & 50.0 & 14 & 50.0 & -0.699 & 0.213 & $0.50(0.166-1.493)$ \\
\hline 3times a week & 20 & 16 & 76.2 & 5 & 23.8 & -2.554 & $0.001 *$ & $0.08(0.017-0.348)$ \\
\hline approximately everyday & 14 & 12 & 85.7 & 2 & 14.3 & -3.379 & $0.001 *$ & $0.03(0.005-0.236)$ \\
\hline \multicolumn{9}{|l|}{ Exposure to cigarette smoking } \\
\hline No & 144 & 79 & 54.9 & 65 & 45.1 & & & \\
\hline Yes & 56 & 21 & 37.5 & 35 & 62.5 & 0.965 & $0.029 *$ & $2.6(1.104-6.237)$ \\
\hline $\begin{array}{l}\text { Average number of cigarette smoked } \\
\text { per day }( \pm \text { std dev) }\end{array}$ & & \multicolumn{2}{|c|}{$8.36 \pm 3.75$} & \multicolumn{2}{|c|}{$8.84 \pm 4.29$} & & 0.317 & $1.09(0.923-1.286)$ \\
\hline \multicolumn{9}{|l|}{ Alcohol Intake Status } \\
\hline No & 40 & 27 & 67.5 & 13 & 32.5 & & & \\
\hline Yes & 160 & 73 & 45.6 & 87 & 54.4 & 1.148 & $0.002 *$ & $3.15(1.541-6.447)$ \\
\hline \multicolumn{6}{|l|}{ Alcohol Type $(\mathrm{n}=160)$} & & \multicolumn{2}{|l|}{0.958} \\
\hline Beer & 50 & 24 & 48.0 & 26 & 52.0 & & & \\
\hline Spirit & 46 & 17 & 37.0 & 29 & 63.0 & 0.188 & 0.670 & $1.21(0.508-2.869)$ \\
\hline Wine & 46 & 23 & 50.0 & 23 & 50.0 & 0.175 & 0.675 & $1.19(0.526-2.695)$ \\
\hline Combined drinks & 18 & 9 & 50.0 & 9 & 50.0 & -0.006 & 0.990 & $0.99(0.368-2.686)$ \\
\hline \multicolumn{9}{|l|}{ Frequency of alcohol intake } \\
\hline Often & 77 & 28 & 36.4 & 49 & 63.6 & & & \\
\hline Sparingly & 83 & 45 & 54.2 & 38 & 45.8 & -1.567 & $0.001 *$ & $0.21(0.103-0.425)$ \\
\hline
\end{tabular}

Asterisks $(*)=5 \%$ significant, coef $=$ coefficient, $\mathrm{CI}=95 \%$ confidence Interval, AOR = Adjusted Odds ratio addition to the number of cigarette smoked per day is likely to attract more risk of T2DM -POAG comorbidity.

Lifestyle factors such as physical exercise, cigarette smoking, and alcohol intake were found significant in the present study. Lower odds were observed for those who engage in exercise for everyday or at least 3 times in a week, compared to subjects that never do exercise while with every single

Higher risk of T2DM -POAG comorbidity was obtained for the study participants that consume alcohol. Intake of alcohol sparingly attracts lesser risk T2DM -POAG comorbidity than taking it frequently. Current alcohol consumption and current 
smoking were both associating factors of diabetes and POAG[19]. Excessive alcohol consumption probably works through the mechanism of insulin resistance which is a key factor in the pathogenesis of T2DM among heavy alcohol consumers.

Cigarette smoking have been reported to confer risk to POAG (Kahn et al, 2011) and T2DM[9]. The possible explanation is that cigarette smoking causes a transient rise in the intraocular pressure through a mechanism of vasoconstriction and elevated episcleral venous pressures. Also high level of nicotine in cigarettes can lessen the effectiveness of insulin causing smokers to need more insulin to regulate blood sugar level.

\section{CONCLUSION}

Lifestyle factors such as active physical exercise, cigarette smoking, and alcohol consumption are cardinal for avoiding the comorbidity of T2DM-POAG among the adults. The present study indicate that having family history of either T2DM or POAG is accompanied with more risk of T2DM-POAG Comorbidity. This study found that the majority of the subjects with the comorbidity of T2DM-POAG have the habit of smoking cigarette.

Research works like this, often tend to broaden the perspectives related to factors that play a vital role during the designing of preventive procedures and development of public health interventions. Thus, this particular research work will definitely prove to be fruitful in the field of Epidemiology and Disease control and other research studies related to public Health, concerned with especially with comorbidity of type 2 diabetes mellitus-primary open angle glaucoma.

\section{REFERENCES}

[1] Chaturvedi, N., Stephenson, J and Fuller, J.(1996). The relationship between Socio-economic status and diabetes control and complications in the EURODIAB IDDM Complications Study. Diabetes Care, 19, 423-430.

[2] Dielemans, I, de Jong,P.T, Stolk,R, Vingerling,J.R, Grobbee,R.D and Hofman. A. (1996). Primary Open-angle Glaucoma, Intraocular Pressure, and Diabetes Mellitus in the General Elderly Population. The Rotterdam Study. Ophthalmology 103(8), 1271- 1275.

[3] Hou, H., Shoji, T., Zangwill, L. M., Moghimi, S., Saunders, L. J., Hasenstab, K., ... Weinreb, R.N. (2018). Progression of Primary Open-Angle Glaucoma in Diabetic and Nondiabetic Patients. American journal of ophthalmology, 189, 1-9. doi:10.1016/j.ajo.2018.02.002

[4] Kahn, S. E., Cooper, M. E. and Del-Prato, S.(2014). Pathophysiology and treatment of type 2 diabetes: perspectives on the past, present, and future. Lancet 383, 1068-1083.

[5] Klein, B E, Klein, R and Jensen,S.C.(1994). Open-angle Glaucoma and Older-onset Diabetes.The Beaver Dam Eye Study.Ophthalmology 101 (7). 1173-1177.

[6] Kyari, F., Entekume, G., Rabiu, M, Paul, S, Wormald, R., Nolan, W., Murthy, G and gilbert, C.E(2015). A Population Based Survey of the Prevalence and Types of Glaucoma in Nigeria: Results from the Nigeria National Blindness \& Visual Impairment Survey. BMC Ophthalmology, 15, 176.
[7] Leske, M. C., Wu, S. Y., Hennis, A., Honkanen, R., and Nemesure, B. (2008). Risk factors for incident open-angle glaucoma: the Barbados Eye Studies. Ophthalmology115, 85-93.

[8] Mitchell, P., Smith, S., Chey, T., and Healey, P.R.(1997). Open-angle glaucoma and diabetes: The Blue Mountains Eye Study, Australia.104,712-718

[9] Nakanishi, N., Nakamura, K., Matsuo, Y et al. (2000). Cigarette Smoking and Risk forImpaired Fasting Glucose and Type 2Diabetes in Middle-Aged Japanese Men, Annals of Internal Medicine, 133, 183191.

[10] Pan, A.(2011). Red meat consumption and risk of type 2 diabetes: 3 Cohorts of US adults and an updated meta- analysis. The American journal of clinical nutrition, 94(4), 1088-1096.

[11] Primus, A.P., Sally, C.B., Alon, H.A., Brent, A., Siesky, S and Giovanna, G. (2011). Diabetes: a Risk Factor for Glaucoma? The British Journal of Ophthalmology, 95(12)1621-1622. doi:10.1136/bjophthalmol- 2011-300788.

[12] Quigley, H.A and Broman, A.T.(2006). The number of people with glaucoma worldwide. Br J Ophthalmol, 90, 262-267.

[13] Quoc, P. S., M. A. Charles, N. H. Cuong, L. H. Lieu, N. A. Tuan, M. Thomas, B. Balkau, and D. Simon. (1994). Blood glucose distribution and prevalence of diabetes in Hanoi (Vietnam). American Journal of Epidemiol139 (7), 713-22.

[14] Shittu, M.O.(2016). Effect of Physical Exercise on Diabetes-Glaucoma Comorbidity Diabetes, 20, 25-28.

[15] Tielsch, J. M., Katz, J., Sommer, A., Quigley, H. A., and Javitt, J. C. (1994) Family history and risk of primary open angle glaucoma. The Baltimore Eye Survey. ArchOphthalmol112, 69-73.

[16] Uloko, A. E., Musa, B. M., Ramalan, M. A., Gezawa, I. D., Puepet, F. H., Uloko, A. T., ... Sada, K. B. (2018). Prevalence and Risk Factors for Diabetes Mellitus in Nigeria: A Systematic Review and Meta-Analysis. Diabetes therapy: research, treatment and education of diabetes and related disorders, 9(3), 1307-1316. doi:10.1007/s13300-018-0441-1

[17] Vincent, C.J.(2012).Is Gender a Risk factor for Type 2 Diabetes Mellistus-A Systematic Review.Sandis Journal Diabetes, 5, 67-69.

[18] Vijaya, L, George, R, Paul, P.G, Baskaran, M, Arvind, H and Raju, P.(2005). Prevalence of Open-angle glaucoma in a rural south Indian Population. Invest Ophthalmol Vis Sci, 46 (12), 4461-4467.

[19] Wise, L. A., Rosenberg, L., Radin, R. G., Mattox, C., Yang, E. B., Palmer, J. R., andSeddon, J. M. (2011). A prospective study of diabetes, lifestyle factors, and glaucoma among African-American women. Annals of epidemiology, 21(6),

$430-439$ doi:10.1016/j.annepidem.2011.03.006

[20] WHO. (2010). Global status report on non-communicable diseases. Accessed May http://www.who.int/nmh/publications/ncd report_full_en.pdf.

[21] Zhao D, Cho J and Kim, M.H.(2014). Diabetes, glucose metabolism, and glaucoma: the 2005-2008 National Health and Nutrition Examination Survey. PLoS One.9, e112460. 